\title{
ASSISTÊNCIA PÚBLICA À SAÚDE NO BRASIL: ESTUDO DE SEIS ANCORAGENS
}

\author{
Ana Maria Cavalcanti Lefèvre* \\ Fernando Lefevre ${ }^{\star \star}$ \\ Maria Rosa Logiodice Cardoso*** \\ Márcia Maria Porto Rossetto Mazza ${ }^{\star \star \star \star ~}$
}

\begin{abstract}
RESUMO: Com vistas a ilustrar aspectos conceituais da técnica de pesquisa qualitativa; Discurso do Sujeito Coletivo, especialmente no que toca à figura metodológica da Ancoragem, o presente trabalho retrata alguns resultados de duas pesquisas: uma sobre satisfação do usuário de serviços de saúde e outra sobre cuidadores de idosos. Objetiva o trabalho também discutir algumas representações sociais sobre a assistência pública à saúde no Brasil atual, obtidas através da análise destas Ancoragens. A análise e a discussão das Ancoragens ressaltam a sua utilidade para o resgate das representações sociais. Quanto a seu conteúdo, estas representações revelam a presença de um conflito entre a lógica universalista do Direito e a lógica do Mercado no imaginário brasileiro atual no campo da saúde o que constitui um indicador claro do processo em curso de mercantilização da saúde no Brasil.
\end{abstract}

PALAVRAS-CHAVE: discurso do sujeito coletivo; ancoragem; assistência à saúde; mercado; direito à saúde

\footnotetext{
* Doutora em Saúde Pública pela FSP/USP; Pesquisadora da PMSP. e-mail: alefevre@ usp.br

** Professor Titular/ Faculdade de Saúde Pública da USP. e-mail: flefevre@usp.br

*** Médica Homeopata. Secretaria de Estado da Saúde do Estado de São Paulo; Dir V. e-mail: mlogiodice@hotmail.com **** Mestranda FSP/USP. Enfermeira Centro de Saúde Escola Geraldo de Paula Souza - Av. Dr. Arnaldo, 715 CEP 01246904 São Paulo/SP. e-mail r.mazza@ig.com.br
} 


\section{INTRODUÇÃO}

O presente trabalho tem dois grandes objetivos: o primeiro retratar, através da apresentação de alguns exemplos, uma das figuras metodológicas (SIMIONI, A.M., 1996) do Discurso do Sujeito Coletivo (DSC) (LEFÈVRE, 2002) que é a Ancoragem; o segundo comentar alguns aspectos do atendimento proporcionado pelos serviços públicos de saúde, através da análise de algumas representações sociais sobre estes serviços.

Este trabalho resgata alguns dos resultados obtidos em duas pesquisas: uma realizada no ano de 2001 cujo objetivo era a avaliação de satisfação da clientela de dois Prontos Socorros das Organizações Sociais de Saúde/SUS/SP (USP, 2002) como parte de um projeto maior de avaliação destas OSS (Termo Aditivo n'01/99) e o outra (em andamento junho de 2002) que faz parte da pesquisa de uma dissertação de mestrado (MAZZA, 2002) sobre cuidadores de idosos.

Como o trabalho versa basicamente sobre a Ancoragem como parte da técnica do Discurso do Sujeito Coletivo desenvolveremos abaixo algumas considerações conceituais sobre o DSC

\section{O DISCURSO DO SUJEITO COLETIVO E ANCORAGEM: CONCEITOS BÁSICOS}

O DSC, enquanto técnica de pesquisa qualitativa é um procedimento de tabulação de depoimentos verbais, que consiste basicamente em analisar o material coletado de entrevistas feitas a partir de um roteiro de questões abertas, extraindo-se de cada uma das respostas as Idéias Centrais e/ou Ancoragens e as suas correspondentes Expressões Chave; com as Expressões Chave das Idéias Centrais ou Ancoragens semelhantes compõe-se um ou vários DSCs, que são discursos-síntese enunciados na primeira pessoa do singular, como se fosse a fala ou o depoimento de uma coletividade.

Os DSC - que podem ser tanto das Idéias Centrais quanto das Ancoragens - podem ser compostos de um ou mais depoimentos que apresentam um sentido singular que, sob uma forma discursiva, refletem os pensamentos e os valores associados a um dado tema, presentes numa dada formação sócio cultural num dado momento histórico.

A título de exemplo, em pesquisa realizada sobre a maconha, num forum proposto pelo Universo on line da Folha de São Paulo (LEFÈVRE,1999) foram identificados seis 
Discursos do Sujeito Coletivo das Idéias Centrais que, na época, puderam fornecer dados relevantes sobre as possibilidades presentes na nossa cultura para pensar a questão do consumo da maconha.

Os instrumentos básicos do Discurso do Sujeito Coletivo são: Idéia Central, Expressão Chave, Ancoragem e Discurso do Sujeito Coletivo:

A Idéia Central (IC) é um nome ou expressão linguística que revela e descreve da maneira mais sintética, precisa e fidedigna possível o sentido das afirmações específicas presentes em cada um dos discursos analisados e em cada conjunto homogêneo de $\mathrm{ECH}$, conjunto esse que vai dar nascimento, posteriormente, ao DSC.

É importante assinalar que a IC não é uma interpretação mas uma descrição do sentido de um depoimento ou de um conjunto de depoimentos.

As Expressões Chave (ECH) são pedaços, trechos ou transcrições literais do discurso, que devem ser sublinhados, iluminados, coloridos, pelo pesquisador, e que revelam a essência do depoimento ou a teoria subjacente

Contida na proposta do Discurso do Sujeito Coletivo temos ainda a figura que denominamos Ancoragem (AC). Por este termo, no contexto aludido e inspirado na teoria da Representação Social (JODELET, 1989; MOSCOVICI, 1978), entendemos um dado conteúdo discursivo presente em um determinado depoimento, que é a manifestação linguística explícita de uma dada teoria, ou ideologia, ou crença, ou valor que o autor do discurso professa e que, na qualidade de afirmação genérica, está sendo usada pelo enunciador para "enquadrar" uma situação específica. É importante observar que todo depoimento tem uma ou várias ICs mas apenas alguns depoimentos apresentam, de maneira explícita, as marcas discursivas da Ancoragem.

Finalmente, o Discurso do Sujeito Coletivo (DSC), enquanto figura metodológica é um discurso-síntese redigido na primeira pessoa do singular e composto pelas ECHs que tem ICs ou ACs semelhantes.

\section{FORMA DE APRESENTAÇÃO}

Serão apresentadas algumas Ancoragens encontradas nas duas pesquisas referidas acima, acompanhadas dos Discursos do Sujeito Coletivo (DSCs) correspondentes. 
Os DSCs das Ancoragens foram compostos com os conteúdos manifestados nas ECHs de um ou mais discursos concretos nos quais estas Ancoragens estão presentes.

\section{RESULTADOS}

\section{QUADRO I}

\begin{tabular}{|c|c|}
\hline ANCORAGEM I & DSC DA ANCORAGEM I \\
\hline $\begin{array}{l}\text { Só os serviços privados, para as } \\
\text { pessoas que podem pagar, proporciona } \\
\text { bom atendimento. }\end{array}$ & $\begin{array}{l}\text { Na época em que estamos vivendo, } \\
\text { coma saúde pública do jeito que está, } \\
\text { a gente que não tem como pagar um } \\
\text { convênio, que ganha muito pouco, o } \\
\text { jeito é recorrer aqui, aos prontos- } \\
\text { socorros. A gente acaba perdendo o } \\
\text { convênio, então você tem que vir pelo } \\
\text { Estado. } \\
\text { Olha, infelizmente, a gente que } \\
\text { depende de hospital público, que } \\
\text { depende do SUS, passa nos hospitais } \\
\text { porque precisa, não porque queira; é } \\
\text { porque realmente precisa, senão a } \\
\text { gente nem viria. } \\
\text { Pior é que é superlotado: aqueles } \\
\text { hospitais que tem o atendimento } \\
\text { melhor, o pessoal procura mais, e a } \\
\text { dificuldade é enorme de ser atendido. } \\
\text { Tem muitos hospitais que até é vazio, } \\
\text { mas, quanto ao atendimento, você } \\
\text { procura um clínico não tem, você } \\
\text { procura um ortopedista não tem, } \\
\text { você procura um ginecologista não tem. } \\
\text { Então é difícil, difícil... a gente vem } \\
\text { porque só tem essa solução, não existe } \\
\text { outra. } \\
\text { Alguns hospitais são bons, é o caso } \\
\text { do Hospital das Clínicas, mas eu não } \\
\text { sei nem como é que ele está lá, se } \\
\text { está tudo cheio, as maca lá; mas se } \\
\text { for não é por causa que o atendimento } \\
\text { seja ruim, é porque é bom, porque vai } \\
\text { muita gente. }\end{array}$ \\
\hline
\end{tabular}




\section{QUADRO ॥}

\begin{tabular}{l|l}
\hline ANCORAGEM II & DSC DA ANCORAGEM II \\
\hline O atendimento é demorado & Não tem condições: quer dizer, nós \\
porque é para pobre; se a pessoa & que é pobre sofre por causa disso. \\
for rica o atendimento é rápido e & Se eu tivesse... se a gente tivesse \\
bom. & dinheiro, aíaparecia médico na hora, \\
& aparecia tudo, todo atendiménto le- \\
& gal. Mas como nós não temos \\
& dinheiro, como nós somos pobres, \\
& não temos dinheiro, então é assim: \\
& "vamos chutar ele para lá, vamos \\
& deixar ele fazer hora; marcar para \\
& agora? Não, deixa para amanhã", \\
& entendeu? É assim. Então é um \\
& sofrimento que a gente passa. \\
\hline
\end{tabular}

Os DSCs 1 e 2 revelam representações nas quais a saúde obtida através do atendimento médico hoje, em nosso país, é percebida como um serviço que espelha uma sociedade marcada pela radical cisão entre ricos e pobres e, conseqüentemente, entre, de um lado, aqueles que tem alternativas e que podem pagar por um serviço que, justamente por ser pago, é de qualidade e, de outro, aqueles que não podem pagar, que não possuem ou que perderam o convênio e que não tem, por isso, outra alternativa senão recorrer ao SUS, ou seja, ao serviço público e gratuito de saúde que, justamente por ser público, gratuito, estatal é de baixa qualidade e não produz satisfação mas, ao contrário, sofrimento naquele que é obrigado a consumi-lo.

Há um sentimento, que exala destas representações, de que o "pobre", pela sua condição econômica, é tratado com desprezo e desconsideração pelos profissionais de saúde ou pelo serviços públicos, em flagrante contraste com o cidadão rico, para o qual há a fantasia de que, simplesmente por ser rico, seria merecedor de um atendimento de qualidade (se a gente tivesse dinheiro, aí aparecia médico na hora, aparecia tudo, todo atendimento legal). 


\section{QUADRO III}

\begin{tabular}{l|l}
\hline ANCORAGEM III & DSC DA ANCORAGEM III \\
\hline $\begin{array}{l}\text { Os serviços de saúde tem obri- } \\
\text { gação de atender bem e os } \\
\text { médicos devem examinar bem, } \\
\text { ser atenciosos e informar com } \\
\text { clareza o que os pacientes tem }\end{array}$ & $\begin{array}{l}\text { Eu acho o seguinte: os médicos eles tem } \\
\text { atenção, não é? Acho que é por obrigação } \\
\text { que eles devem atender às pessoas direito, } \\
\text { porque se não atender direito, ninguém } \\
\text { consegue se passar a moléstia. } \\
\text { Também tem que ter paciência e saber } \\
\text { explicarpara a gente bem o problema, para } \\
\text { que a gente possa ter uma noção do que } \\
\text { realmente está acontecendo; por que às } \\
\text { vezes não é uma coisa, é outra. }\end{array}$ \\
\hline
\end{tabular}

O DSC 3 mostra que o atendimento de saúde precisa ser, por parte do profissional médico, detalhado, cuidadoso, minucioso, compreensível pelo usuário porque se isto não ocorrer não estará havendo um real atendimento médico.

Este DSC revela uma representação de natureza técnica, que é distinta da anterior, mais social. A representação técnica difere da social porque é interna e não externamente centrada, já que seu objeto é a natureza ou o propósito mesmo do serviço, ou seja o diagnóstico e a cura da moléstia e não, como no caso anterior, o contexto social, responsável pela divisão de classes em ricos e pobres, pela injustiça social que decorre desta divisão e pelas repercussões desta injustiça na qualidade do atendimento de saúde.

De outro ângulo podemos dizer que, tendo as três representações como pano de fundo a assistência à saúde oferecida pela rede pública, a primeira e a segunda (os DSCs 1 e 2) colocam frente a frente os atores sociais em conflito, revelando a distribuição desigual do serviço de saúde que prevalece entre nós, brasileiros, enquanto que a segunda ( $O$ DSC3) diz respeito à relação médico-paciente, ou seja, a uma relação entre seres que, antes de serem sociais, são humanos. 


\section{QUADRO IV}

\begin{tabular}{l|l}
\hline ANCORAGEM IV & DSC DA ANCORAGEM IV \\
\hline $\begin{array}{l}\text { Os hospitais públicos em geral não } \\
\text { oferecem um bom atendimento. No } \\
\text { começo é bom depois mudam para } \\
\text { pior.. }\end{array}$ & $\begin{array}{l}\text {..então eu fico naquela expectativa: "será } \\
\text { eles podem fazer um raio-x, uma coisa } \\
\text { assim, parecida, que resolva ? Porque a } \\
\text { gente sabe que é público, mas eu já vim } \\
\text { aqui e eu gostei. } \\
\text { É, para um hospital público, esse daqui } \\
\text { está de parabéns. Espero que não seja } \\
\text { só promessa, não é? Que a maioria dos } \\
\text { hospitais no começo é uma maravilha, } \\
\text { depois muda. }\end{array}$ \\
\hline
\end{tabular}

ODSC 4 revela a possibilidade de uma mudança na qualidade do serviço oferecido pelo sistema público de saúde, mas esta possibilidade é ainda permeada pela dúvida, pela expectativa,pela incerteza porque o objeto da mudança é justamente o serviço público, cuja representação é forte e tradicionalmente marcada por traços de ineficiência.

Por isso há o medo da frustração das expectativas em função provavelmente de muitas experiências anteriores de promessas nessa direção não cumpridas. 


\section{QUADRO V}

\begin{tabular}{l|l}
\hline ANCORAGEM V & DSC DA ANCORAGEM V \\
\hline $\begin{array}{l}\text { Os médicos atendem bem por- } \\
\text { que esta é a profissão deles }\end{array}$ & $\begin{array}{l}\text { Acho que os médicos, todos os médicos } \\
\text { atende bem, não é? A profissão deles é } \\
\text { essa: atender. Agora, se quiser também, } \\
\text { eles manda encaminhar, manda fazer. }\end{array}$ \\
\hline
\end{tabular}

O DSC 5 marca a presença de uma importante representação também de caráter técnico que é interessante porque mostra que visão corporativa da profissão médica (=todo médico é bom por ser médico; todos os médicos atendem bem porque são profissionais do atendimento; quando eles não podem diretamente atender encaminham para outro profissional médico que possa) não é socialmente regional mas socialmente inclusiva na medida em que está presente também na sociedade em geral: não é só categoria médica que é corporativa, mas a sociedade como um todo também compartilha esta representação.

\section{QUADRO VI}

\begin{tabular}{l|l}
\hline ANCORAGEM VI & DSC DA ANCORAGEM VI \\
\hline Quem não tem plano de saúde & $\begin{array}{l}\text { Que na segunda-feira eu falei, vamos lá } \\
\text { tem que fazer prevenção }\end{array}$ \\
& né, porque como não paga o plano de \\
& saúde, não tem nada, tem que estar \\
& sempre né, fazendo aquilo que o pessoal \\
& fala, prevenção, né. \\
\hline
\end{tabular}


O DSC 6, retirado de uma pesquisa sobre cuidadores de idosos (op. cit). retoma, sob outro ângulo, a questão da injustiça social e de suas repercussões na desigualdade em saúde, na medida em que postula que aquele que não tem ou não pode pagar plano de saúde não "tem nada" ou seja não é merecedor de qualquer assistência médica, ficando, por isso, obrigado a adotar condutas preventivas.

Poderíamos dizer que a desigualdade em saúde se expressa, também, como este discurso ilustra bem, no status secundário e subalterno (em relação à assitência curativa) da prevenção, reservada aos pobres, incapazes de arcar com as despesas de um plano de saúde e que, por isso, não tem direito à doença.

\section{DISCUSSÃO}

\section{A importância da Ancoragem como figura metodológica do Dsc}

O DSC como técnica de agregação de depoimentos nos permite conhecer o conjunto de representações sociais sobre determinados temas prevalentes numa dada coletividade que, sob a forma de um conjunto de discursos, configura uma determinada cadeia significante e argumentativa.

Ora, tal cadeia, justamente por ser um discurso, por constituir uma cadeia argumentativa e pelo discurso estar enunciado na primeira pessoa, em termos peirceanos, acaba constituindo um poderoso interpretante (PIERCE, C.S, 1975) para estas representações na medida que viabiliza, metodologicamente, o acesso a elas tornando-as mais claras e explícitas e também porque potencializa sua comunicabilidade e seu impacto nos receptores.

\section{A importância pedagógica da Ancoragem}

Mas o DSC nos permite ir ainda mais a fundo nas representações. Com efeito, na medida em que o conjunto dos DSC das Idéias Centrais nos possibilita conhecer o que pensa e como age uma dada coletividade, o conjunto dos DSC das Ancoragens nos possibilita conhecer as bases, as teorias, as motivações, as crenças, os valores, enfim, os princípios que embasam as representações daquela comunidade pesquisada. 
Por isso, poderíamos dizer que os DSCs das Ancoragens permitem que emerjam um certo tipo de representações mais fortes, mais nucleares, mais abrangentes, menos regionais, como diria Bourdieu (BOURDIEU, 1990).

Ora, este tipo de representações que resgatam as Ancoragens tem grande importância quando se considera o uso pedagógico ou educativo da pesquisa qualitativa. Isto porque, como as Ancoragens revelam o fundamento ideológico das representações, permitem descortinar ao pesquisador as "causas" destas representações, o que seria de grande valia quando do planejamento de uma intervenção pedagógica destinada a provocar mudanças em valores básicos da coletividade pesquisada.

O DSC, na medida em que aparece como um discurso de um sujeito coletivo emitido na primeira pessoa do singular, como se fosse um indivíduo real falando, no chamado momento devolutivo da pesquisa qualitativa (GOLDENBERG, 1999) ou seja quando os resultados estão sendo repassados para a população pesquisada, ou para uma amostra semelhante à população pesquisada, permite que o pesquisado seja visto e se veja com muita clareza e vivacidade, permitindo com isso uma forte identificação com os resultados obtidos na pesquisa.

Assim sendo, a devolução para uma coletividade do DSC das Ancoragens permitiria, ou aumentaria a chance da tomada de consciência por parte de uma coletividade de seus valores mais arraigados e abrangentes, dando condições para aumentar significativamente a eficiência e eficácia das ações educativas, na medida em que esta tomada de consciência poderia ensejar mudanças comportamentais de amplo alcance, que podem incidir sobre uma variada gama de comportamentos mais específicos que estão embasados nestes valores.

\section{Assistência à saúde: serviço ou direito?}

Pesquisas como a que foi realizada junto às OSS (op.cit) sugerem a hipótese de que entre nós, hoje, a assistência à saúde aparece, destacadamente, nas representações sociais nas quais é o tema, com a marca de um tipo de serviço cujo prestígio está estreitamente associado à incorporação de tecnologia, e que é prestado no seio de uma sociedade cujo eixo é o mercado. Como afirmam COHN \& ELIAS: "Segundo o ideário difundido por essas agências internacionais (Bid e Banco Mundial), cabe fundamentalmente ao Estado a função de provedor da universalização dos serviços básicos de saúde, reservando-se, no 
entanto, ao mercado o acesso aos serviços mais especializados e de alta complexidade tecnológica" (p. 98).

Em tais sociedades, então, serviços como os de saúde tem sua qualidade diretamente associada a seu preço: quanto mais caro melhor, quanto mais barato (e, neste caso, a gratuidade associada ao serviço público quer dizer preço zero) pior.

Nesse sentido a lei do Sistema Único de Saúde cujo eixo é o Direito sugere a existência entre nós, hoje, no que toca à saúde, de um conflito de eixos: de um lado o eixo do Direito, que postula e decreta legalmente que todo ser humano nascido no Brasil, independentemente da sua condição sócio econômica, tem direito não apenas à saúde mas, mais concretamente, à assistência à saúde e de outro o eixo do Mercado (alguns diriam, maldosamente que o eixo do mercado seria, freudianamente falando, o princípio da realidade enquanto o eixo do direito seria o do prazer ou da fantasia...) postulando que a saúde e a assistência à saúde de cada brasileiro é diretamente proporcional ao preço e às vantagens oferecidas por seu plano de saúde.

\section{CONCLUSÃO}

A proposta do Discurso do Sujeito Coletivo como uma tecnologia do arsenal da pesquisa qualitativa e, dentro dela, a figura metodológica da Ancoragem, parecem constituir instrumentos úteis para recuperar aspectos relevantes das Representações Sociais em Saúde presentes na sociedade e na cultura brasileiras contemporâneas.

No que diz respeito especificamente ao conteúdo destas representações que enfocam o tema da assistência à saúde oferecida pelos serviços públicos de saúde, notase claramente uma tendência característica da sociedade brasileira contemporânea como um todo que consiste num duplo movimento articulado de ascensão do Mercado e de queda do Direito.

\section{REFERÊNCIAS BIBLIOGRÁFICAS}

BOURDIEU, P. Coisas ditas. São Paulo, Brasiliense,1990 
COHN, A; ELIAS, P.E.M. (coords) O público e o privado na saúde - o PAS em São Paulo. São Paulo: Cortez, 1999.

LEFEVRE, F.; LEFEVRE, A.M.C.; TEIXEIRA, J.J.V. (Orgs) O Discurso do Sujeito Coletivo. Uma nova abordagem metodológica em pesquisa qualitativa. Caxias do Sul, Educs, 2002.

LEFÈVRE, F. \& SIMIONI, A.M.C. Maconha, saúde, doença e liberdade. Análise de um forum na Internet. Cadernos de Saúde Pública, Rio de Janeiro, v. 15 n. 2, p. 161-7. 1999.

GOLDENBERG., M. A arte de pesquisar. Como fazer pesquisa qualitativa em ciências sociais. $3^{\mathrm{a}}$ ed., Rio de Janeiro: Record, 1999.

JODELET, D. Représentations sociales: un domaine en expansion. In: JODELET, D. (org). Les représentations sociales. Paris: PUF, 1989. p.

MAZZA, M.M.R.P. Cuidar em familia: análise da representação social do relação cuidadorfamiliar. Pesquisa para dissertação de mestrado (em andamento). São Paulo, Faculdade de Saúde Pública da USP, 2002.

MOSCOVICl, S. A representação social da psicanálise. Rio de Janeiro, Zahar, 1978

PIERCE, C.S. Semiótica e filosofia. São Paulo, Cultrix/Edusp, 1975.

SÃO PAULO (Estado). Termo aditivo n ${ }^{\circ}$ 01/99 ao convênio celebrado em 31/10/1996 entre o Governo do Estado de São Paulo, a Secretaria de Estado da Saúde e a Faculdade de Saúde Pública da Universidade de São Paulo.

SIMIONI, A.M.C. O gerenciamento de recursos humanos em saúde como processo social. São Paulo, 1996. [Dissertação de Mestrado em Saúde Pública da Faculdade de Saúde Pública da Universidade de São Paulo]

UNIVERSIDADE DE SÃO PAULO - Faculdade de Saúde Pública Sub Projeto de Avaliação de Satisfação da Clientela. São Paulo, 2002. Relatório de Pesquisa. 


\section{PUBLIC HEALTH CARE IN BRAZIL: A STUDY OF SIX ANCHORAGES}

SUMMARY: In order to illustrate conceptual aspects of a qualitative research tool - the Collective Subject Speech - especially in relation to the methodological concept of Anchorage the present work portrays some results of two pieces of research. The first on the public user's satisfaction towards health services and the second on elderly caretakers. Also, this work aims at discussing some current social representations on public health assistance in Brazil through the analysis of these Anchorages. The analysis and the discussion of the Anchorage highlights its usefulness for the rescuing of social representations. In their content these representations disclose a conflict between the general logic of the Right and that of the Market in the current Brazilian imaginary on the health field. Such conflict clearly indicates health's ongoing merchantilizing process in Brazil.

KEY WORDS: collective subject speech, anchorage, health care, market, health rights. 